\title{
The evolution of infrahissian conduction time in myotonic dystrophy patients: clinical implications
}

\author{
Bénédicte Lallemand, ${ }^{1}$ Nicolas Clementy, ${ }^{1}$ Anne Bernard-Brunet, ${ }^{1}$ Bertrand Pierre, ${ }^{1}$ \\ Philippe Corcia, ${ }^{2}$ Laurent Fauchier, ${ }^{1}$ Martine Raynaud, ${ }^{3}$ Sybille Pellieux, ${ }^{4}$ \\ Dominique Babuty ${ }^{1}$
}

${ }^{1}$ Cardiology Department, Hospital Trousseau, François Rabelais University, Tours, France

${ }^{2}$ Neurology Department, Hospital Bretonneau, François Rabelais University, Tours, France

${ }^{3}$ Genetics Department, Hospital Bretonneau, François Rabelais University, Tours, France ${ }^{4}$ Functional Readaptation Department, Hospital Trousseau, François Rabelais University, Tours, France

\section{Correspondence to}

Professor Dominique Babuty, Cardiology Department, Hospital Trousseau, François Rabelais University, 37044 Tours, France; d.babuty@chu-tours.fr

Accepted 14 September 2011 Published Online First 29 October 2011

\begin{abstract}
Background Myotonic dystrophy (MD1) is a hereditary autosomal dominant disease with variable penetrance. Cardiac conduction disturbances are frequent and may be responsible for sudden death, but its progression was heretofore unknown.
\end{abstract}

Aims The aim of the study was to analyse the natural history of infrahissian conduction time in patients with a normal first electrophysiological test, and to identify the predictive value of the clinical and ECG factors accompanying an alteration of infrahissian conduction. Methods Among 127 consecutive screened MD patients, 25 were enrolled and underwent a second electrophysiological testing. The second electrophysiological test was carried out on patients showing new symptoms, new atrioventricular conduction disturbances on ECG, or significant modifications of signal-averaged (SA)-ECG, and on asymptomatic patients with a follow-up of at least 60 months since the first electrophysiological test.

Results Among the 25 patients, four had new clinical symptoms, four others developed new atrioventricular conduction abnormalities on ECG and six had significant modifications of the SA-ECG. The mean His-ventricle (HV) interval increased significantly between the two electrophysiological studies (initial HV interval $52.1 \mathrm{~ms} \pm 1.6 \mathrm{~ms}$, final HV interval $61.4 \mathrm{~ms} \pm 2.2 \mathrm{~ms}$, $p<0.005)$, with a mean increase of $1.2 \mathrm{~ms} /$ year. The five patients with HV interval of $70 \mathrm{~ms}$ or greater were implanted with a prophylactic dual-chamber pacemaker. Modifications of resting ECG and SA-ECG were strongly associated with HV interval prolongation.

Conclusion In patients with a normal initial electrophysiological study, modifications on the resting ECG and/or SA-ECG, on annual check-up, were associated with an alteration of infrahissian conduction.

Myotonic dystrophy (MD1), the most frequent adult form of muscular dystrophy, is a hereditary autosomal dominant disease with variable penetrance that occurs in one to 10 persons out of $100000 .^{1}$ It is caused by a mutation on the long arm of chromosome 19 in the form of an unstable expansion of cytosine-thymine-guanine (CTG) repeats in the untranslated region of the gene for myotonin protein kinase. ${ }^{2} \mathrm{MD} 1$ leads to multiple systemic complications, essentially related to muscular weakness, respiratory failure, cardiac arrhythmias and cardiac conduction disturbances. In the $\mathrm{MD}$ population, the age of death is lower than in the general population, ${ }^{3-5}$ and the frequency of sudden death is higher. ${ }^{3-11}$ The 2002 study by Lazarus et al ${ }^{12}$ demonstrated that a pacemaker should be implanted in patients with $\mathrm{MD}$ if their His-ventricle (HV) interval is $70 \mathrm{~ms}$ or greater, even if they are asymptomatic, in order to protect them from the clinical consequences of profound bradycardia and to facilitate the diagnosis and management of frequent paroxysmal tachyarrhythmias. A high incidence of complete atrioventricular block (AVB) was recorded on memory pacemaker in $\mathrm{MD}$ patients with a $\mathrm{HV}$ interval of $70 \mathrm{~ms}$ or greater implanted with a prophylactic pacemaker. $^{12} 13$

Moreover, Laurent et al ${ }^{13}$ observed a very low incidence rate of sudden death in $\mathrm{MD}$ patients $(0.2$ / 100 patient-years) selected to receive a prophylactic pacemaker on the basis of $\mathrm{HV}$ interval duration. The benefit of prophylactic pacemaker implantation was also confirmed in $\mathrm{MD}$ patients estimated to be at high risk of sudden death in accordance with Groh's ECG factors. ${ }^{513}$ These previous results are a powerful argument in favour of the usefulness of electrophysiological testing in $\mathrm{MD}$ patients to select the candidates for prophylactic pacemaker implantation. However, infrahissian conduction is not stable over time and tends to increase in $\mathrm{MD}$ patients. ${ }^{14}$ So one unresolved question is when should the electrophysiological testing be repeated in $\mathrm{MD}$ patients without a pacemaker. In our study of a large population of monitored MD patients, we analysed the natural history of infrahissian conduction time and tested the predictive value of the clinical, resting ECG, and signal-averaged (SA)ECG parameters of an alteration of infrahissian conduction (prolongation of $\mathrm{HV}$ interval $\geq 70 \mathrm{~ms}$ ).

\section{METHODS}

\section{Population}

All patients with MD1 confirmed by genetic and electromyographic study and treated by our university institution's multidisciplinary team for the care of patients with neuromuscular disease were recruited. Some of the patients included in the present study have already been described in previous studies. ${ }^{1315} \mathrm{New}$ patients with MD1 who were presented to the multidisciplinary team due to recent disease diagnosis, or new symptoms or new resting ECG abnormalities were also include in this study. Clinical data were prospectively collected and evaluated every year. The annual check-up consisted of a physical examination by online under the BMJ Journals unlocked scheme, see http:// heart.bmi.com/site/about/ unlocked.xhtml 
a cardiologist, a neurologist and a chest specialist. Functional status, supplemented by the recording of resting ECG, SA-ECG and pulmonary capacity, was monitored once a year. The $\mathrm{MD}$ patients without pacemakers and who had previously undergone an electrophysiological study were selected for our study. A second electrophysiological study was proposed to the patients in the event of new symptoms (unexplained syncope or presyncope, palpitations), new atrioventricular conduction disturbances on annual resting ECG, significant modifications of SA-ECG with respect to the previous study, ${ }^{15}$ and atrial arrhythmias justifying anti-arrhythmic drugs, or in asymptomatic patients with a follow-up of at least 60 months. This time interval between the first and second electrophysiological tests in asymptomatic patients was chosen from the study of Prystowsky et $a l^{14}$ who reported a $5 \mathrm{~ms}$ prolongation of the HV interval over a 3 -year period in several patients, and from the study of Laurent et al, ${ }^{13}$ who reported a complete AVB in one patient with a normal HV interval 5 years earlier. Therefore, 60 months after the first electrophysiological test the HV interval would be prolonged by $10 \mathrm{~ms}$ and could exceed $70 \mathrm{~ms}$. Once identified, $\mathrm{MD}$ patients with these criteria underwent electrophysiological testing after informed consent was obtained and signed. Patients who were initially studied less than 60 months without new symptoms, or without significant changes in resting ECG or SA-ECG were not considered for a new electrophysiological study.

\section{Electrophysiological testing}

The electrophysiological testing was performed using standard techniques with two quadripolar catheters introduced into the femoral vein and worked up into the bundle of His region of the right atrium. Several variables were measured during the electrophysiological study: atrial-His (AH) interval (ms), HV interval (ms), atrioventricular Wenckebach points (beats/min) during right atrial stimulation at increasing rate, sinus node recovery time (ms). The criterion for proposing a prophylactic pacemaker implantation was a HV interval of $70 \mathrm{~ms}$ or greater. Programmed right ventricular stimulation was not performed.

\section{Signal-averaged ECG}

Recordings were performed using Simson's method with an ART recorder (model 120; Arrhythmia Research Technology, Austin, Texas, USA). The ECG was recorded with standard bipolar orthogonal X, Y, Z leads. Signals were amplified, averaged and filtered with bidirectional filtered frequencies of $40-250 \mathrm{~Hz}$. As previously reported, ${ }^{15}$ the association of ORSD (total ORS duration) of $100 \mathrm{~ms}$ or greater and LAS40 (duration of low amplitude signal $<40 \mu \mathrm{V}$ ) of $36 \mathrm{~ms}$ or greater on SA-ECG contributes to the identification of $\mathrm{MD}$ patients with a prolonged HV interval. Five patients reported in the previous study in 1999 were also included in the present study. These criteria are not those commonly used to identify patients at risk of sustained ventricular tachycardia post-myocardial infarction, but in $\mathrm{MD}$ they are linked to infrahisian conduction alteration and not to ventricular arrhythmia substrate. ${ }^{16}$

\section{Study endpoints}

The primary endpoint was to evaluate the evolution over time of the infrahissian conduction time in adult $\mathrm{MD}$ patients. The second endpoint was to define the predictive clinical and electrocardiographic parameters of a severe alteration in infrahissian conduction time that would justify a repetition of electrophysiological testing in $\mathrm{MD}$ patients with a view to proposing the prophylactic implantation of a pacemaker.

\section{Statistical analysis}

Data were reported as the mean $\pm \mathrm{SD}$. Baseline characteristics in patients with and without prolonged HV interval were compared using univariate analysis and the Fisher's exact test for qualitative parameters and the Mann-Whitney test for quantitative parameters. The correlation between the variation of HV interval (HV2-HV1) and the size of the mutation was analysed using the linear regression method. A p value less than 0.05 was considered significant.

\section{RESULTS}

Starting in 1994, 70 of 127 consecutively screened patients with MD1 were not initially implanted with a pacemaker. All patients were classified as having an adult-onset form of $\mathrm{MD}$. The clinical characteristics of these 70 patients are summarised in table 1. Twenty-five of these 70 patients were enrolled and underwent a second electrophysiological testing. Figure 1 shows the enrolment of the study population. No significant differences were observed between the initial clinical characteristics of the 25 patients enrolled in the present study (age, sex, Brooke score, Epworth score, resting ECG, right and left ventricular ejection fraction, CTG amplification) and the 45 patients who did not initially receive a pacemaker (table 1) and who were not enrolled in the present study for different reasons set out in figure 1. The upgraded clinical characteristics of the 25 patients undergoing a second electrophysiological study are summarised in table 2.

Neurological functional status was evaluated by the Brooke score. ${ }^{17}$ The severity of muscular weakness was scored at the level of arms (range from 1 to 6 ) and legs (range from 1 to 10). It ranged from 2 to 11 in our patients. Four patients had a score of 5 or greater. Only two patients were confined to a wheelchair. No patient was under permanent mechanical respirator at the time of the second electrophysiological testing. The excessive daytime sleepiness was evaluated by the Epworth sleepiness scale with eight items. ${ }^{18}$ Each item accounts for $0-3$ points. Sleep apnoea syndrome was diagnosed with standard polysomnographic studies in 11 patients. This sleep apnoea syndrome was treated by nocturnal non-invasive positive pressure ventilation in eight patients. Eleven patients had cataracts and 12 had alopecia. The mean value of creatine phosphokinase

Table 1 Initial mean characteristics of the MD patients without a pacemaker

\begin{tabular}{llll}
\hline & $\begin{array}{l}\text { Group 1 }(n=70) \\
\text { mean } \pm \text { SD }\end{array}$ & $\begin{array}{l}\text { Group 2 }(\mathbf{n}=45) \\
\text { mean } \pm \text { SD }\end{array}$ & $\begin{array}{l}\text { Group 3 }(\mathbf{n}=\mathbf{2 5}) \\
\text { mean } \pm \text { SD }\end{array}$ \\
\hline Age (years) & $40 \pm 15$ & $41.5 \pm 15$ & $37.2 \pm 14$ \\
Women n, (\%) & $28(40)$ & $21(46)$ & $7(28)$ \\
Brooke score & $3.3 \pm 2.3$ & $3.4 \pm 2.6$ & $3.4 \pm 1.7$ \\
Abnormal ECG & $20(28.5)$ & $14(31.1)$ & $8(32)$ \\
Spontaneous AF, $\mathrm{n}(\%)$ & $8(11)$ & $6(13.3)$ & $2(8)$ \\
Spontaneous NSVT, $\mathrm{n}$ & 1 & 1 & 0 \\
LVEF (\%) & $59.4 \pm 10$ & $57.2 \pm 10.7$ & $62.3 \pm 9.1$ \\
LVEF <50\%, n & 9 & 7 & 2 \\
RVEF (\%) & $44.2 \pm 10$ & $43.2 \pm 11$ & $46.2 \pm 8$ \\
LVEDD (mm) & $46.5 \pm 4$ & $47.5 \pm 5$ & $45.6 \pm 5$ \\
CTG repeat length Kb & $2.1 \pm 1.5$ & $2 \pm 1.6$ & $2.4 \pm 1.3$ \\
\hline
\end{tabular}

Group 1 all patients without pacemaker in our global myotonic dystrophy (MD) population group 2 patients excluded from the present study for different reasons explained in figure 1 ; group 3 patients enrolled in the study who underwent two electrophysiological studies. Group 1 versus group 2 versus group 3 not significant differences for all parameters. $\mathrm{AF}$, atrial fibrillation; CTG, cytosine-thymine-guanine; LVEDD, left ventricular end-diastolic dimension; LVEF, left ventricular ejection fraction; NSVT, non sustained ventricular tachycardia; RVEF, right ventricular ejection fraction. 


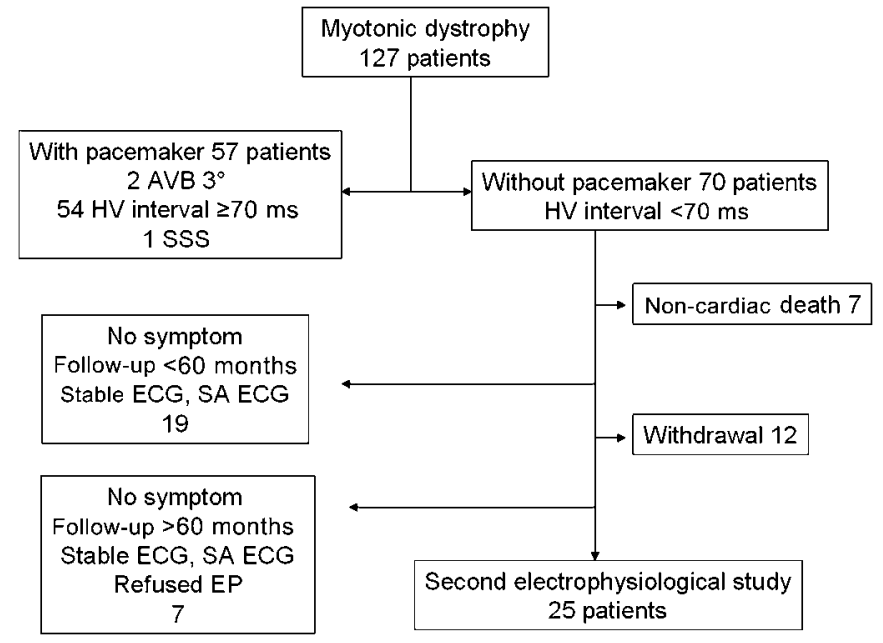

Figure 1 Myotonic dystrophy patient enrolment. Among 70 patients without pacemakers, 25 underwent a second electrophysiological test. AVB, atrioventricular block; EP, electrophysiological test; HV, Hisventricle; SA-ECG, signal-averaged ECG.

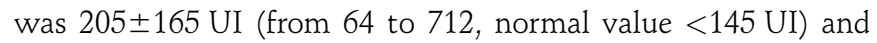
five patients had significant vesicular lithiasis.

Left ventricular ejection fraction was normal (>50\%) in 21 patients (84\%) and slightly altered in four patients (ranging from $45 \%$ to $50 \%$ ). Right ventricular radionuclide function was available for 13 patients and was normal in four of them $(>45 \%)$ and slightly altered in nine others (ranging from $30 \%$ to $45 \%$ ).

\section{ECG patterns}

Initially, 17 patients (68\%) showed normal conduction intervals on their first ECG. Among the remaining patients, four had left anterior block, two had isolated $1^{\circ} \mathrm{AVB}$, one had $1^{\circ} \mathrm{AVB}$ associated with right bundle branch block, and one had both right bundle branch block and left anterior block. At the time of the second electrophysiological test only four patients had developed new atrioventricular conduction abnormalities (table 2). One patient presented with a symptomatic bradytachycardia syndrome. The evolution of ECG is summarised in table 3.

Five patients had paroxysmal atrial arrhythmias. Atrial fibrillation was treated by amiodarone $(\mathrm{n}=1)$ which does not severely depress the infrahisian conduction. ${ }^{19}$ Atrial flutter was treated by cavo-tricuspid isthmus ablation $(n=1)$. Three patients were

Table 2 Upgraded clinical characteristics of the patients who underwent a second electrophysiological test

\begin{tabular}{ll}
\hline & $\begin{array}{l}\text { Patients (n=25) } \\
\text { mean } \pm \text { SD (range) }\end{array}$ \\
\hline Age (years) & $44 \pm 13.6(24-73)$ \\
Women, n (\%) & $7(28)$ \\
Brooke score & $3.4 \pm 2.5(2-11)$ \\
Epworth score & $6.8 \pm 4.5(0-17)$ \\
Abnormal ECG, n (\%) & $10(40)$ \\
Spontaneous atrial arrhythmias, n (\%) & $5(20)$ \\
Spontaneous NSVT, n (\%) & 0 \\
LVEF (\%) & $58 \pm 9(45-75)$ \\
LVEF <50\% n & 4 \\
RVEF (\%) & $40 \pm 6(30-54)$ \\
LVEDD (mm) & $46 \pm 4(37-52)$ \\
CTG repeat length Kb & $2.4 \pm 1.3(0.5-5.5)$
\end{tabular}

CTG, cytosine-thymine-guanine; LEVD; LVEDD, left ventricular end-diastolic dimension; LVEF, left ventricular ejection fraction; NSVT, non sustained ventricular tachycardia; RVEF, right ventricular ejection fraction. not treated by anti-arrhythmic drugs because the atrial arrhythmias were not symptomatic.

On $24 \mathrm{~h}$ ECG, paroxysmal AVB of second and third degree was not observed.

\section{Signal-averaged ECG}

Modifications of SA-ECG reaching the significant cut-off defined by QRSD of $100 \mathrm{~ms}$ or greater and LAS of $36 \mathrm{~ms}^{15}$ or greater were observed in six patients.

In one patient, SA-ECG was invalid because of the level of noise, and in another it could not be performed due to a technical problem. The mean values of SA-ECG parameters were: ORSD $105 \pm 10.8 \mathrm{~ms}$, under $4036.5 \pm 12 \mathrm{~ms}$, HFRMSA (root mean square voltage of signals in the last $40 \mathrm{~ms}$ of the ORS complexes) $30.3 \pm 24.7 \mu \mathrm{V}$.

\section{Electrophysiological testing}

The mean age at the second electrophysiological test was $44.4 \pm 13.6$ years. The mean interval between the first and the second electrophysiological test was $90.8 \pm 36$ months (minimum 24 months, maximum 144 months). Four patients were given the second electrophysiological test because they developed new symptoms, four others on account of modifications in resting ECG, one other for a bradytachycardia syndrome, only three for abnormal SA-ECG, and 13 patients merely because the follow-up exceeded 60 months. In asymptomatic patients with no ECG or SA-ECG modification, the mean interval between the first and the second electrophysiological test tended to be longer than in other patients $(101 \pm 34$ months versus $81 \pm 29$ months, NS). At the second electrophysiological test the $\mathrm{HV}$ interval was $70 \mathrm{~ms}$ or greater in five cases $(20 \%)$. The mean value of the HV interval increased significantly between the two electrophysiological tests (figure 2 and table 3). The Wenckebach point was $154 \pm 29$ beats/min. No infrahissian block was provoked by increasing atrial stimulation. Sinus node function was abnormal in one patient. The mean corrected sinus node recovery time was $297 \pm 246 \mathrm{~ms}$. Five patients with HV interval of $70 \mathrm{~ms}$ or greater were implanted with a prophylactic dual-chamber pacemaker. The patient with bradytachycardia syndrome was given an oral anti-arrhythmic agent, amiodarone $200 \mathrm{mg} /$ day and a pacemaker.

\section{Characteristics of patients with abnormal HV interval}

The five patients with a HV interval of $70 \mathrm{~ms}$ or greater at the second electrophysiological test showed a modification in their resting ECG over time $(n=4)$ or significant modifications in the SA-ECG $(n=3)$ (table 3 and figure 2). One of the MD patients with stable resting ECG, despite a prolonged HV interval, showed significant lengthening of SA-ECG parameters (patient 24 in table 3). ORSD and under 40 tended to be longer in the prolonged $\mathrm{HV}$ interval group than in normal HV interval group (ORDS 109.8 \pm 6 vs $103.6 \pm 11 \mathrm{~ms}$, under $40 \quad 42.4 \pm 18$ vs $34 \pm 9.6 \mathrm{~ms})$. The mean duration of the follow-up was not significantly different between the group of patients with a HV interval of $70 \mathrm{~ms}$ or greater at the second electrophysiological test and those without a HV interval of $70 \mathrm{~ms}$ or greater at the second electrophysiological test $(80 \pm 46$ vs $93.5 \pm 34$ months, NS). None of the clinical characteristics were significantly different between the two groups in terms of age, severity of muscular weakness and frequency of sleep apnoea syndrome; nor was the size of the mutation significantly different in those patients $(2.5 \pm 1.1$ vs $2.2 \pm 1.9 \mathrm{~kb}$, NS). No correlation was established between the variation in the HV interval and the size of the mutation $\left(\mathrm{r}^{2}=0.03\right.$, NS). 
Table 3 Electrophysiological characteristics of patients who underwent a second electrophysiological study

\begin{tabular}{|c|c|c|c|c|c|c|c|c|}
\hline Patients & ECG 1 & HV $1 \mathrm{~ms}$ & $\begin{array}{l}\text { Indication 2nd } \\
\text { electrophysiological study }\end{array}$ & $\begin{array}{l}\text { Time interval between } \\
\text { EP in months }\end{array}$ & ECG 2 & SA-ECG2 & HV $2 \mathrm{~ms}$ & Pacemaker \\
\hline 1 & Normal & 45 & Follow-up & 75 & Normal & Negative & 50 & No \\
\hline 2 & Normal & 55 & Follow-up & 136 & Normal & Negative & 55 & No \\
\hline 3 & Normal & 35 & $\mathrm{CP}$ and palpitations & 48 & Normal & Negative & 50 & No \\
\hline 4 & $\mathrm{LAB}$ & 50 & Follow-up & 58 & LAB & Positive & 60 & No \\
\hline 5 & AVB $1+$ RBBB & 58 & Presyncope & 48 & AVB $1+$ RBBB & Negative & 65 & No \\
\hline 6 & AVB 1 & 60 & ECG modification & 24 & AVB 1 & Negative & 80 & Yes \\
\hline 7 & Normal & 50 & ECG modification & 108 & $\mathrm{LAB}$ & Positive & 70 & Yes \\
\hline 8 & Normal & 40 & Follow-up & 118 & Normal & Positive & 45 & No \\
\hline 9 & Normal & 55 & Follow-up & 78 & Normal & Negative & 60 & No \\
\hline 10 & Normal & 55 & Follow-up & 132 & Normal & Negative & 55 & No \\
\hline 11 & Normal & 30 & Syncope & 50 & Normal & Negative & 50 & No \\
\hline 12 & Normal & 50 & Follow-up & 144 & Normal & Negative & 60 & No \\
\hline 13 & Normal & 50 & ECG modification & 132 & LBBB & $\dagger$ & 90 & Yes \\
\hline 14 & $\mathrm{LAB}$ & 55 & Follow-up & 132 & $\mathrm{LAB}$ & Negative & 50 & No \\
\hline 15 & Normal & 60 & Follow-up & 96 & Normal & Negative & 60 & No \\
\hline 16 & $\mathrm{LAB}+\mathrm{RBBB}$ & 60 & ECG modification & 96 & AVB $1+\mathrm{LAB}+\mathrm{RBBB}$ & Positive & 80 & Yes \\
\hline 17 & AVB 1 & 50 & Follow-up & 72 & AVB 1 & - & 50 & No \\
\hline 18 & $\mathrm{LAB}$ & 50 & Follow-up & 96 & $\mathrm{LAB}$ & Negative & 60 & No \\
\hline 19 & $\mathrm{LAB}$ & 55 & Follow-up & 142 & $\mathrm{LAB}$ & Negative & 65 & No \\
\hline 20 & Normal & 50 & Bradytachycardia & 72 & Normal & Negative & 55 & Yes* \\
\hline 21 & Normal & 60 & SA-ECG + & 43 & Normal & Negative & 60 & No \\
\hline 22 & Normal & 50 & Follow-up & 120 & Normal & Negative & 65 & No \\
\hline 23 & Normal & 60 & Syncope, SA-ECG + & 90 & Normal & Positive & 60 & No \\
\hline 24 & Normal & 60 & SA-ECG + & 40 & Normal & Positive & 80 & Yes \\
\hline 25 & Normal & 60 & Follow-up & 120 & Normal & Negative & 60 & No \\
\hline
\end{tabular}

Signal-averaged (SA)-ECG was regarded as the presence of QRSD of $100 \mathrm{~ms}$ or greater and LAS40 of $36 \mathrm{~ms}$ or greater. $^{15}$

*Pacemaker implanted for brady-tachycardia syndrome.

tInvalid because of noise.

AVB 1, atrioventricular block 1; CP, chest pain; EP, electrophysiological testing; HV, His-ventricle; LAB, left anterior block; LBBBG, left bundle branch block, RBBB, right bundle branch block.

\section{Predictive value of resting ECG and SA-ECG}

Resting ECG is very useful for the identification of patients with an alteration of infrahissian conduction. Of the five patients with a new prolongation of the HV interval, four showed significant modification in their resting ECG. Only one patient without modification of ECG had a prolonged HV interval (sensitivity $80 \%$, specificity $99 \%$ ).

SA-ECG was significantly modified in six patients but was associated with prolonged interval in only three patients (sensitivity $100 \%$, specificity $50 \%$ ).

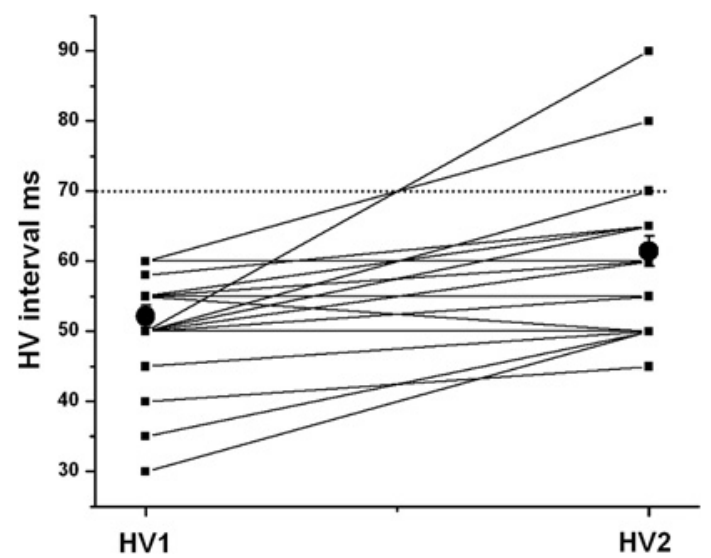

Figure 2 Evolution of His-ventricle (HV) interval (ms) in myotonic dystrophy patients. Full black square: individual HV interval at the first electrophysiological study (HV1) and at the second electrophysiological study (HV2) Full black circles: mean value of HV interval $\pm E S(p<0.001)$.
The combination of modifications of resting ECG and SA-ECG identified all patients with prolonged HV interval (sensitivity $100 \%$ and specificity $75 \%$ ).

\section{DISCUSSION}

This study, for the first time, shows the evolution of the resting ECG and SA-ECG characteristics and of the HV interval in non-selected adult $\mathrm{MD}$ patients monitored every year in the same reference centre. Some significant modifications of resting ECG were observed in four patients and abnormal SA-ECG in six patients, and were strongly associated with an HV interval prolongation. The HV interval increase was not linked to any new symptoms such as syncope or palpitations, or to the duration of the follow-up.

Nguyen et $a l^{20}$ reported that abnormalities of the cardiac conduction system were commonly observed in $\mathrm{MD}$ due to frequent fatty infiltration and fibrosis of the His bundle. The electrophysiological consequences of these histopathological lesions were frequent infrahissian conduction disturbances on electrophysiological testing (prolonged HV interval) and a high risk of complete $\mathrm{AVB}$ in $\mathrm{MD}$ patients. ${ }^{12} 1321$ In animal models for dystrophy myotonic protein kinase (DMPK) reduction the same histopathological lesions and His Purkinje system alterations were reported. ${ }^{22}$ A time-dependent degenerative process has been suggested by Groh et al, ${ }^{23}$ who observed a correlation between age and ECG abnormalities, and by Prystowsky et al, ${ }^{14}$ who in serial electrophysiological studies demonstrated the progression of infrahissian conduction time in a small number $(n=9)$ of non-consecutive MD patients. However, in the large study by Laurent et al, ${ }^{13}$ including $51 \mathrm{MD}$ patients with 
a normal HV interval of less than $70 \mathrm{~ms}$ followed up during $57 \pm 36$ months, only one patient developed a complete AVB, 52 months after the initial electrophysiological testing, whereas 19 of 49 patients with HV interval of $70 \mathrm{~ms}$ or greater developed $3^{\circ}$ AVB. These results suggest two categories of adult $\mathrm{MD}$ patients: one characterised by early infrahissian conduction disturbances ( $\mathrm{HV}$ interval $\geq 70 \mathrm{~ms}$ ) frequently risking complete $\mathrm{AVB}$, and a second category of adult $\mathrm{MD}$ patients who may exhibit a very slow progression of infrahissian conduction time. This hypothesis is consistent with our results, which through serial electrophysiological testing demonstrated a progression of $\mathrm{HV}$ interval in only five of 25 patients during a prolonged period of 90 months as opposed to Prystowsky et al, ${ }^{14}$ who reported an aggravation of HV interval in seven of nine selected patients during a short 3 -year period. This difference can be explained by the high rate of abnormal resting ECG (7/9) and prolonged HV interval (3/9) at the initial evaluation in the Prystowsky study. ${ }^{14}$ Second, the high prevalence of complete AVB documented in memory pacemaker in $\mathrm{MD}$ patients with an early $\mathrm{HV}$ interval of $70 \mathrm{~ms}$ or greater points to a severe evolution of the infrahissian conduction time in this subgroup of patients. ${ }^{12} 13$ This heterogeneity of $\mathrm{MD}$ patients in terms of infrahissian characteristics is compatible with the heterogeneity of the size of the mutation in the different organs (somatic mosaicism), which is not exactly the same for leucocytes. No correlation has been established between respiratory insufficiency, weakness, or cardiac disease, probably because the effect of the non-translated CTG repeat expansion is not unique but multiple $e^{24}$ and is not uniform from one patient to another.

A second major finding of our study is the strong relationship between the evolution of cardiac conduction disturbances on resting ECG and the increase in the HV interval in a serial study. No correlation between resting ECG and HV interval or histopathological lesions ${ }^{12} 141520$ has been reported in the literature, but the previous studies did not integrate the dynamism of the atrioventricular conduction parameters in their analysis. In our study patients with a significant increase in the HV interval corresponded approximately to those with a significant progression of cardiac conduction abnormalities on resting ECG. Mörner et $a l^{25}$ pointed out the importance of analysing the progression of the atrioventricular conduction disturbances on ECG. A progressive increase in PR interval and ORS duration on resting ECG has been demonstrated as being statistically associated with higher mortality in MD patients. ${ }^{10} 25$ Groh et al showed in a large population of $\mathrm{MD}$ patients that the resting ECG was a crucial key in defining those patients at high risk of sudden death. In the subgroup of patients at high risk of sudden death in accordance with the Groh criteria, Laurent et $a l^{13}$ showed that the implantation of a prophylactic pacemaker in the presence of a prolonged HV interval decreased the incidence of sudden death. Therefore, the evaluation of the risk of sudden death should be re-checked by ECG every year. Ventricular arrhythmias are the second mechanism evoked to explain sudden death but the method of identifying $\mathrm{MD}$ patients at risk is unknown. Ventricular arrhythmias induced during electrophysiological study do not predict spontaneous ventricular arrhythmias. ${ }^{16}$ We can only suggest discussing the implantation of an implantable cardioverter defibrillator instead of a pacemaker in $\mathrm{MD}$ patients with prolonged $\mathrm{HV}$ interval and depressed left ventricular ejection fraction below 30\%. ${ }^{26}$

Breton and Mathieu ${ }^{11}$ proposed integrating the analysis of QT interval on resting ECG to identify $\mathrm{MD}$ patients at risk of sudden death or pacemaker implantation. In presence of a OT interval longer than $450 \mathrm{~ms}$ the age-adjusted $\mathrm{RR}$ was 3 .
However, rigorous analysis of the QT interval remains a major problem. ${ }^{27}$ An automatic analysis and a dynamic analysis on $24 \mathrm{~h}$ ECG with the help of new software could be interesting to limit the variability of the QT interval measurement.

SA-ECG is a useful tool in evaluating the infrahissian conduction characteristics of $\mathrm{MD}$ patients. ${ }^{15}$ Babuty et al ${ }^{15}$ demonstrated that an association of QRSD of $100 \mathrm{~ms}$ or greater and LAS of $36 \mathrm{~ms}$ or greater selects patients with a prolonged $\mathrm{HV}$ interval of $70 \mathrm{~ms}$ or greater with high sensitivity (80\%) and specificity (83.3\%). In the present study significant changes in the SA-ECG correlate with prolonged HV interval in three of six patients. The combination of resting ECG and SA-ECG appears to be the best method of identifying patients showing an alteration over time of the infrahissian conduction time, with excellent sensitivity (100\%) and acceptable specificity (75\%). However, the usefulness of SA-ECG to identify MD patients with prolonged infrahisian conduction has not been validated by an another group.

\section{Limitations of the study}

The fact that not all the patients without a pacemaker were systematically re-investigated could introduce a bias in this study. However, we have verified that the clinical characteristics of the 25 patients included in the study did not differ statistically from the 45 patients not re-investigated for different reasons (table 1 and figure 1 ).

Some patients could have a normal ECG and prolonged HV interval due to a short $\mathrm{AH}$ interval. ${ }^{12}$ These patients, however, can be identified by the SA-ECG, which, as previously mentioned in the discussion, accurately reveals infrahissian conduction abnormalities.

For the moment there is no randomised, controlled study in the literature clearly indicating that preventive pacemaker implantation in patients with a $\mathrm{HV}$ interval greater than $70 \mathrm{~ms}$ decreases mortality and morbidity in $\mathrm{MD}$. Only observational and non-controlled studies suggest a real benefit from the prophylactic implantation of a pacemaker in the presence of a prolonged $\mathrm{HV}$ interval of $70 \mathrm{~ms}$ or greater. ${ }^{12} 13$

\section{CONCLUSION ON CLINICAL IMPLICATIONS}

The infrahissian conduction disturbances frequently observed in adult $\mathrm{MD}$ patients justify the early identification of patients with a prolonged HV interval, who are at high risk of complete AVB. This can be done by carrying out an early electrophysiological study at the time of $\mathrm{MD}$ diagnosis. Prophylactic implantation of a pacemaker should be proposed to patients with a HV interval of $70 \mathrm{~ms}$ or greater. In patients with an initially normal infrahissian conduction time on the electrophysiological study, the risk of complete AVB is very low, and a second electrophysiological study should be performed only in the event of modifications in atrioventricular conduction ECG parameters or SA-ECG in annual check-ups. In the future, it will be important to conduct a controlled and randomised study in order to demonstrate clearly the benefits of prophylactic pacemaker implantation in MD patients with a HV interval of $70 \mathrm{~ms}$ or greater.

Acknowledgements The authors are indebted to Mr Stephen Randel, native English assistant, for re-reading the manuscript.

\section{Competing interests None.}

\section{Patient consent Obtained.}

Contributors BL contributed to the design of the study, analysed the results and wrote the paper; NC performed the electrophysiological study and read the paper; 
AB-B performed the echocardiography and electrophysiological study; BP performed the electrophysiological study and analysed the results; PC recruited the patients; LF performed some of the electrophysiological study and analysed the results; MR did the genetic analysis; SP recruited the patients; DB contributed to the design of the study, supervised the study and wrote the paper.

Provenance and peer review Not commissioned; externally peer reviewed.

\section{REFERENCES}

1. Emery AE. Population frequencies of inherited neuromuscular diseases-a world survey. Neuromuscul Disord 1991;1:19-29.

2. Harley HG, Rundle SA, Reardon W, et al. Unstable DNA sequence in myotonic dystrophy. Lancet 1992;339:1125-8.

3. Phillips MF, Harper PS. Cardiac disease in myotonic dystrophy. Cardiovasc Res 1997:33:13-22.

4. de Die-Smulders CE, Howeler CJ, Thijs C, et al. Age and causes of death in adultonset myotonic dystrophy. Brain 1998;121:1557-63.

5. Groh WJ, Groh MR, Saha C, et al. Electrocardiographic abnormalities and sudden death in myotonic dystrophy type 1. N Engl J Med 2008;358:2688-97.

6. Mladenovic J, Pekmezovic T, Todorovic S, et al. Survival and mortality of myotonic dystrophy type 1 (Steinert's disease) in the population of Belgrade. Eur $\mathrm{J}$ Neurol 2006; 13:451-4.

7. Nishioka SA, Martinelli Filho M, Marie S, et al. Myotonic dystrophy and heart disease: behavior of arrhythmic events and conduction disturbances. Arq Bras Cardiol 2005;84:330-6

8. Mathieu J, Allard P, Potvin L, et al. A 10 -year study of mortality in a cohort of patients with myotonic dystrophy. Neurology 1999;52:1658-62.

9. Reardon W, Newcombe R, Fenton I, et al. The natural history of congenital myotonic dystrophy: mortality and long-term clinical aspects. Arch Dis Child 1993;68:177-81.

10. Sabovic M, Medica I, Logar N, et al. Relation of CTG expansion and clinical variables to electrocardiogram conduction abnormalities and sudden death in patients with myotonic dystrophy. Neuromuscul Disord 2003;13:822-6.

11. Breton R, Mathieu J. Usefulness of clinical and electrocardiographic data for predicting adverse cardiac events in patients with myotonic dystrophy. Can J Cardiol 2009;25:e23-7.

12. Lazarus A, Varin J, Babuty D, et al. Long-term follow-up of arrhythmias in patients with myotonic dystrophy treated by pacing: a multicenter diagnostic pacemaker study. J Am Coll Cardiol 2002;40:1645-52.
13. Laurent V, Pellieux $S$, Corcia $P$, et al. Mortality in myotonic dystrophy patients in the area of prophylactic pacing devices. Int J Cardiol 2011;150:54-8.

14. Prystowsky EN, Prichett EL, Roses AD, et al. The natural history of conduction system disease in myotonic muscular dystrophy as determined by serial electrophysiologic studies. Circulation 1979;60:1360-4

15. Babuty D, Fauchier L, Tena-Carbi D, et al. Is it possible to identify infrahissian cardiac conduction abnormalities in myotonic dystrophy by non-invasive methods? Heart 1999:82:634-7.

16. Babuty D, Fauchier L, Tena-Carbi D, et al. Significance of late ventricular potentials in myotonic dystrophy. Am J Cardiol 1999;84:1099-101.

17. Brooke MH. A Clinical's View of Neuromuscular Diseases, 1st edn. Baltimore William \& Wilkins, 1997:277.

18. Johns MW. A new method for measuring daytime sleepiness: the Epworth sleepiness scale. Sleep 1991;14:540-5.

19. Ikeda N, Nademanee K, Kannan R, et al. Electrophysiologic effects of amiodarone: experimental and clinical observations relative to serum and tissue concentrations. Am Heart J 1984;108:890-8.

20. Nguyen HH, Wolfe JT, Holmes DR, et al. Pathology of the cardiac conduction system in myotonic dystrophy: a study of 12 cases. J Am Coll Cardiol 1988;11:662-71.

21. Olofsson B0, Forsberg $H$, Andersson $\mathrm{S}$, et al. Electrocardiographic findings in myotonic dystrophy. Br Heart J 1988;59:47-52.

22. Saba S, Vanderbrink BA, Luciano $B$, et al. Localization of the sites of conduction abnormalities in a mouse model of myotonic dystrophy. J Cardiovasc Electrophysiol 1999;10:1214-20.

23. Groh WJ, Lowe MR, Zipes D. Severity of cardiac conduction involvement and arrhythmias in myotonic dystrophy type 1 correlates with age and CTG repeat length. J Cardiovasc Electrophysiol 2002;13:444-8.

24. Tapscott SJ, Thornton CA. Biomedecine. Reconstructing myotonic dystrophy Science 2001;293:816-17.

25. Mörner S, Lindqvist P, Mellberg C, et al. Profound cardiac conduction delay predicts mortality in myotonic dystrophy type 1. Int J Med 2010;268:59-65.

26. Epstein AE. ACC/AHA/HRS 2008 Guidelines for Device-Based Therapy of Cardiac Rhythm Abnormalities. A report of the American College of Cardiology/American Heart Association Task Force on Practice Guidelines (writing committee to revise the ACC/AHA/NASPE 2002 guideline update for implantation of cardiac pacemakers and antiarrhythmia devices). J Am Coll Cardiol 2008;51:1-62.

27. Rautaharju PM, Surawicz B, Gettes LS. AHA/ACCF/HRS recommendations for the standardization and interpretation of ECG. Part IV: the ST segment, T and U waves, a QT interval. J Am Coll Cardiol 2009;53:982-91. 